\title{
Leadership \& Professional Development: Authentic Impact: Grow Your Influence by Building Your Brand
}

\author{
Manuel J Diaz, MD*, Emily Gottenborg, MD
}

'Division of Hospital Medicine, Department of Medicine, University of Colorado School of Medicine, Aurora, Colorado.

"Knowing yourself is the beginning of all wisdom."-Aristotle

On the wards, your white coat and stethoscope signal your role as a healthcare provider. These external symbols of your work represent your expertise, experience, and commitment to service, and your patients look to these signals for comfort and reassurance. But when you are running a meeting, managing projects, or leading people in your organization, how do others know what you have to offer? Although signaling your values, skills, and intentions is as important in leadership as it is in the clinical setting, few clinicians spend time reflecting on how best to do this. Crafting a strong, consistent personal leadership brand can help.

As described by Norm Smallwood and Dave Ulrich, a personal leadership brand is the external projection of your strengths and interests, which demonstrates how you create value for others. ${ }^{1,2}$ In other words, a personal leadership brand helps constituents, stakeholders, and potential partners understand what you offer as a leader. Having a brand keeps you on track as a leader and helps get you noticed for future opportunities by helping you shape and meet expectations in a way that is deliberate, dynamic, and authentic.

Building your personal leadership brand is an exercise in reflection. Leaders should challenge themselves to answer the following questions:

- What do I have to offer, and what do others appreciate about me?

-What are my values?

- Where am I trying to go?

- How does my path align with organizational goals?

The answers to these simple questions can help you create your personal leadership brand. First, reflect on what you want to be known for, your values, and how you are currently perceived. Then, identify the results you are aiming to produce, aligning them with your strengths and organizational goals. Write these down, and share your reflections with trusted peers

*Corresponding Author: Manuel J. Diaz, MD; Email: Manuel.Diaz@ucdenver. edu; Telephone: 720-848-4289.

Received: August 16, 2019; Accepted: August 16, 2019

(c) 2020 Society of Hospital Medicine DOI 10.12788/jhm.3318 and your mentoring team. Shape your thoughts into a personal vision statement with a focus on what you put out into the world to help you stay true to yourself while producing the desired results. For example, a vision statement for a gifted communicator with a background in quality improvement may be: "I will use my strong communication skills to address complex problems impacting our hospital to reduce cost and improve quality with the goal of building a career as a health system leader." Finally, be authentic, and share your personal brand in an articulate and succinct way to help others understand your place in the structure and narrative of an organization.

Your personal leadership brand should not be static; rather, it is a process that should iterate over time. Ask for direct feedback from trusted advisers and allies at regular intervals. Investigate whether your organization offers a formal structure, such as a "360 Evaluation," to get perspective on how your unique strengths, skills, and goals are perceived. Then, explore and clarify discrepancies between where you think you are and how others see you. Approaching these conversations with humility will keep you aligned with your values, which makes it easier for others to be invested in your development.

A strong personal leadership brand is a force multiplier, providing clarity within teams and helping align a leader's assets and values with organizational goals. It is a solid external signal of what others can expect from your work and will help you focus on your strengths while identifying areas for growth. A personal leadership brand is formed through reflection and, at its core, its authenticity. In the words of Paracelsus, a Renaissance physician, astrologer, and alchemist, "Be not another, if you can be yourself." ${ }^{3}$

Disclosures: The authors have nothing to disclose.

\section{References}

1. Smallwood N. Define your personal leadership brand in five steps. Harvard Business Review. March 29, 2010. https://hbr.org/2010/03/define-your-personal-leadershi.

2. Ulrich D, Smallwood N. Leadership brand: developing customer-focused leaders to drive performance and build lasting value. Harvard Business Review. August 13, 2007. https://hbr.org/2007/07/building-a-leadership-brand.

3. Grandjean P. Paracelsus revisited: the dose concept in a complex world. Basic Clin Pharmacol Toxicol. 2016;119(2):126-132. https://doi.org/10.1111/ bcpt.12622. 